\title{
A prospective study to compare levonogestrol intrauterine system and trans-cervical resection of endometrium for treatment of abnormal uterine bleeding
}

\author{
Kishorkumar V. Hol, Shraddha S. Shastri*, Shilpa S. Magar, Sameer P. Darawade
}

Department of Obstetrics and Gynecology, Smt. Kashibai Navale Medical College Narhe, Pune, Maharashtra, India

Received: 11 September 2019

Accepted: 15 November 2019

*Correspondence:

Dr. Shraddha S. Shastri,

E-mail: drshradds@gmail.com

Copyright: () the author(s), publisher and licensee Medip Academy. This is an open-access article distributed under the terms of the Creative Commons Attribution Non-Commercial License, which permits unrestricted non-commercial use, distribution, and reproduction in any medium, provided the original work is properly cited.

\begin{abstract}
Background: This article is a study comparing the two most accepted forms of treatment for abnormal uterine bleeding - levonorgestrol intrauterine treatment and transcervical resection of endometrium, with regards to its acceptability, efficacy, adverse effects and user satisfaction. Aim of this study was to compare the acceptability, efficacy, adverse effects and user satisfaction of LNG-IUS and TCRE for treatment for AUB.

Methods: A prospective observational study conducted in SKNMC and GH. Forty-nine women with abnormal uterine bleeding after hysteroscopic evaluation were included in this study; where 17 opted for LNG-IUS; 32 opted for TCRE with bipolar electrode. 15 patients in LNG-IUS group and 28 pts in TCRE group completed follow up. Menstrual pattern, pictorial blood loss assessment chart score, adverse effects, acceptability, satisfaction and reason for discontinuation were recorded at 6 weeks, 6 months and 12 months after the procedure. Prior to LNG-IUS insertion or endometrial ablation, endometrial and cervical pathology were excluded by D and C and cervical smear, respectively. TVUS was used to exclude possible causes of menorrhagia, including myomas and endometrial polyp as well as adnexal pathology. LNG-IUS insertion was performed as an office procedure one day after cessation of menstrual bleeding with a negative urine pregnancy test.

Results: Menstrual blood loss reductions in TCRE and LNG-IUS groups were by $85.7 \%$ and $87.6 \%$ respectively after a year. Amenorrhoea was more common in TCRE group while spotting and systemic effects were more common in LNG-IUS group. Satisfaction and acceptance rates are higher in TCRE group.

Conclusions: The TCRE and LNG-IUS are equally effective in reducing bleeding in AUB patients. Acceptance and satisfaction are better with TCRE, as a modality of treatment for AUB.
\end{abstract}

Keywords: Abnormal uterine bleeding, Amenorrhea, Endometrium, Levonorgesterol intrauterine system, Transcervical resection of menorrhagia

\section{INTRODUCTION}

women bring to their clinicians. Approximately 10-15\% of women have HMB1, defined as a menstrual blood loss (MBL) of $>80 \mathrm{ml}$. It is often incapacitating and expensive to treat and can severely affect a woman's quality of life. ${ }^{1}$ Many women are not happy with medical treatment due to prolonged duration and adverse effects so end up undergoing surgery. Hysterectomy was once the only surgical option for heavy menstrual bleeding and almost half of hysterectomies currently performed worldwide are carried out for this reason. ${ }^{2}$ Oestrogens cause nausea, vomiting and thrombo-embolic complications. Progestogens are preferred to oestrogens 
in the peri-menopausal women. Progestogens when taken orally cause nausea, vomiting, bloating, mastalgia, and depression. Surgical treatment such as hysterectomy and endometrial ablation techniques require hospitalization and anesthesia. ${ }^{2}$ The risks of surgical intervention, anaesthetic complications and surgical site infection are considerable.

Endometrial destruction techniques destroy or remove the endometrium. Introduced in the 1980s were:

- First generation techniques - direct hysteroscopic vision - roller ball ablation and trans-cervical resection

- Second generation non hysteroscopic techniques devices are sited and activated to treat the whole endometrial cavity simultaneously without visual control.

\section{$L N G$}

Levonorgestrel intrauterine system which was initially introduced as an intrauterine contraceptive device has recently been used for the treatment of heavy menstrual bleeding. Intrauterine delivery of progestin is an effective way to administer local treatment and bypass systemic side effects. It has emerged as an alternative to the usual medical and surgical methods of treatment for AUB. ${ }^{3}$ Antifibrinolytic agents reduce the bleeding by $40-50 \%$, prostaglandin synthetase inhibitors reduce the bleeding by $20-25 \%$, oral contraceptives reduce the bleeding by $40-50 \%$, and LNG-IUS reduces the bleeding by $86-97 \%$. LNG-IUS has shown the greatest reduction in menstrual blood loss, and, hence has been proposed as an alternative to hysterectomy in perimenopausal women. ${ }^{3}$ LNG-IUS can reduce the menstrual blood loss by $92.9 \%$ (97.6-81.1\%) and help to improve anemia. ${ }^{4}$ LNG-IUS is also a very good alternative for women who have HMB and desire contraception. ${ }^{5}$ LNG-IUS is useful in treating HMB in obese women. ${ }^{6}$ LNG-IUS is safe in women who have undergone prior surgeries such as cesarean or myomectomy. LNG-IUS is beneficial in the treatment of uterine fibroid, endometriosis, adenomyosis and endometrial hyperplasia. ${ }^{7}$ Health related quality of life outcomes and cost effectiveness with LNG-IUS was found to be similar to hysterectomy or endometrial ablation in several developed countries. ${ }^{8}$

Objective of this study was to compare the acceptability, efficacy, adverse effects and user satisfaction of LNGIUS and TCRE for treatment for AUB.

\section{METHODS}

Prospective observational study conducted from October 2016 to April 2017 with a total 49 women with abnormal uterine bleeding after hysteroscopic evaluation were included in this study. Of these, 17 opted for LNG-IUS; 32 opted for TCRE with bipolar electrode. A total 15 patients in LNG-IUS group and 28 patients in TCRE group completed follow-up

Menstrual pattern, pictorial blood loss assessment chart score, adverse effects and rates of acceptability and satisfaction, reason for discontinuation were recorded at 6 weeks, 6 months and 12 months after the procedure.

Prior to LNG-IUS insertion or endometrial ablation, endometrial pathology (endometrial carcinoma and/or endometrial atypical hyperplasia) and cervical pathology (cervical cancer and preinvasive intraepithelial lesions) were excluded by $\mathrm{D}$ and $\mathrm{C}$ and cervical smear, respectively. TVUS was used to exclude possible possible causes of menorrhagia, including myomas and endometrial polyp as well as adnexal pathology. Women participating in the study reported the duration of uterine bleeding in days prior to, and six months and 12 months after each intervention. LNG-IUS insertion was performed as an office procedure one day after cessation of menstrual bleeding.

All women had a negative urine pregnancy test prior to LNG-IUS insertion. The uterine cavity length was measured using uterine sounding followed by LNG-IUS insertion.

\section{Inclusion criteria}

- $\quad$ AUB unresponsive to medical treatment.

- Family completed

- No genital infection

- Malignancy ruled out with biopsy

- Ready to accept TCRE as treatment modality

- Uterine size with less than 8 weeks.

\section{Exclusion criteria}

- Undue due to severe medical illness

- Unacceptable for oligomenorrhoea or amenorrhoea

- Women with uterine or adnexal pathology

- Women desiring preservation of fertility

- Endometrial and cervical carcinoma.

\section{The LNG-IUS}

LNG-IUS consists of a $32 \mathrm{~mm} \mathrm{~T}$ shaped polyethylene frame with a reservoir containing $52 \mathrm{mg}$ of levonorgestrel. The LNG-IUS releases $20 \mu \mathrm{g}$ of levonorgestrel per day.

A plasma concentration of $150-200 \mathrm{pg} / \mathrm{ml}$ is achieved after a few weeks. The Figure 1 shows the structure of LNG-IUS. The plasma concentration of levonorgestrel in LNG-IUS users is $25 \%$ less than that seen when $150 \mu \mathrm{g}$ of levonorgestrel is taken orally.

The slow release of levonorgestrel in the uterine cavity suppresses the endometrium and causes endometrial 
glandular atrophy and stromal decidualization. Levonorgestrel: potent blocker of oestrogen activity on the endometrium; thickens the cervical mucus. All these actions of levonorgestrel on the endometrium and the cervix make LNG-IUS an effective contraceptive and a non-surgical minimally invasive long-term treatment option for menorrhagia. ${ }^{8}$

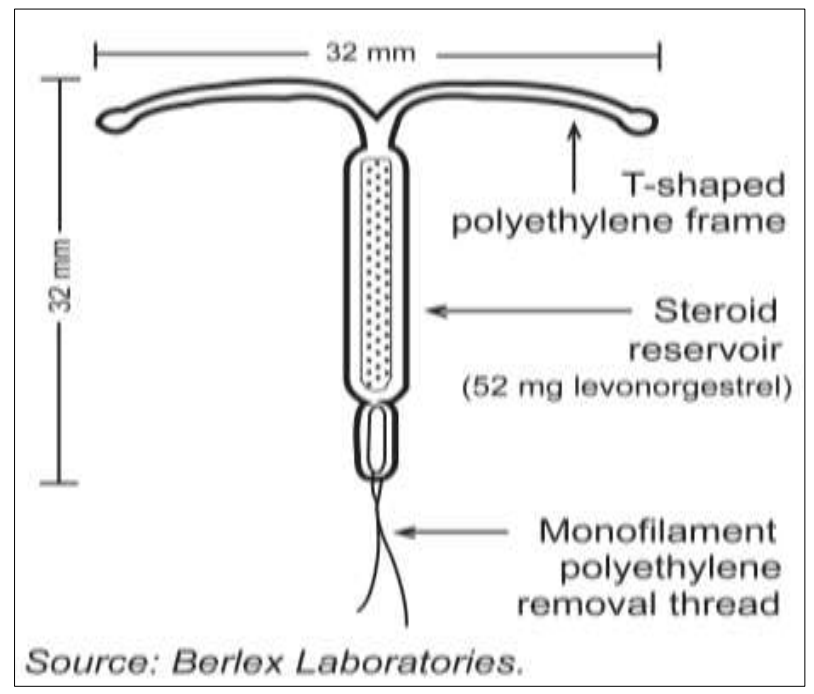

Figure 1: Structure of LNG-IUS.

It is highly effective, with a typical-use first year pregnancy rate of $0.1 \%$ - similar to surgical tubal occlusion. It is approved for 5 years of contraceptive use, and there is evidence that it can be effective for up to 7 years of continuous use. After removal, there is rapid return to fertility, with 1-year life-table pregnancy rates of 89 per 100 for women less than 30 years of age. Most users experience a dramatic reduction in menstrual bleeding, and about $15 \%$ to $20 \%$ of women become amenorrheic 1 year after insertion.

\section{Indication}

- Contraception during reproductive age and 4 weeks postpartum

- Hypermenorrhea

- Endometrial protection during estrogen substitution.

\section{Contraindications}

- Ongoing pregnancy

- $\quad$ < weeks post-partum

- Immediate post-abortion

- Cancer - cervix, uterus, breast

- Post septic abortion

- Anatomical abnormalities distorting uterine cavity

- Pelvic inflammatory disease - current or within last 3 months

- Pelvic tuberculosis

- Unexplained uterine bleeding

- Postpartum endometritis
- Acute hepatic affections and liver tumor; severe cirrhosis;

- Thromboembolic diseases; coagulation disorders or use of anticoagulant medicines;

- Severe anemia

- Immunosuppressive therapy

- Frequent sexual partner changes

- Hypersensitivity to levonorgestrel or to another component.

\section{Precautions}

Exclude endometrial pathology; without any uterine bleeding after six weeks of use, a pregnancy test is required; epilepsy; diabetes; ovarian cyst; uterine scars; history of ectopic pregnancy; non-steroidal antiinflammatory drug use.

Gynaecological examination before insertion, 12 weeks after and then annually.

Target population: women of reproductive age, from 6 weeks up to one year postpartum who are actively breastfeeding at least 4 times per day. The method is WHO medical eligibility criteria (since the third edition in 2004), and the selected practice recommendations for contraceptive use (sine the second edition in 2004). There is currently no medicated intra-uterine device available on the EML.

Others: LNG-20 IUS - release of $20 \mu \mathrm{g}$ levonorgestrel /day occurs during the first year, $11 \mu \mathrm{g}$ per day after 5 years with an average of $14 \mu \mathrm{g}$ per day over 5 years.

Duration: LNG-releasing IUS is effective for five years.

Diagnostic: LNG-releasing IUS used for reversible contraception.

\section{Insertion}

LNG-IUS should be inserted during the first seven days of the cycle. Post-partum insertion can be done six weeks after normal delivery and twelve weeks after caesarean section.

The levonorgestrel-releasing intrauterine system, LNG20 IUS is included in the WHO medical eligibility criteria for contraceptive use, Fourth edition, 2009, the Selected practice recommendations for contraceptive use, second edition 2004 and the family planning global handbook for providers, 2011 update.

\section{TCRE}

After gradual dilatation of the uterine cervix (Hegar size up to 10.5), a 26F operative hysteroscope was inserted (Storz company, Tuttlingen, Germany). The Figure 2 
shows the resectoscope and the system used for TCRE. The uterine cavity was distended using isotonic solution.

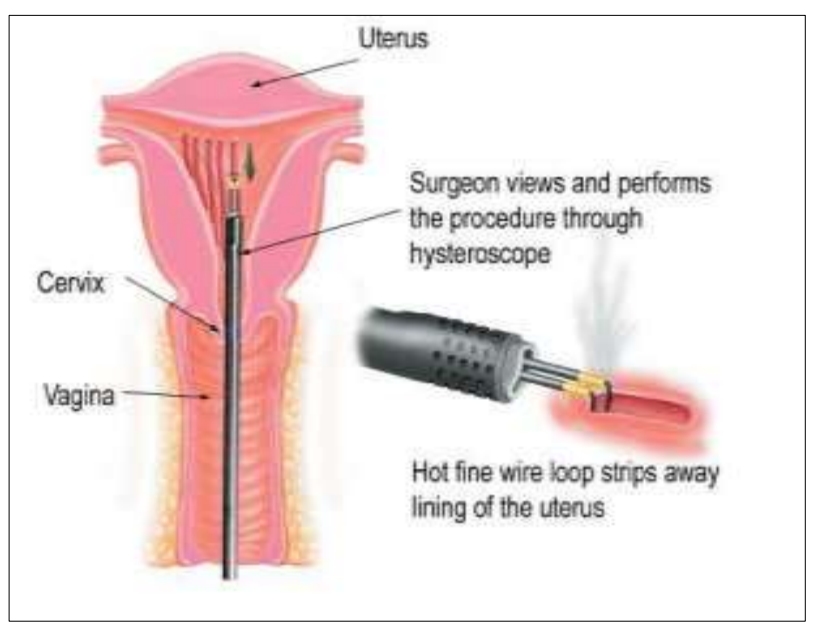

Figure 2: Resectoscope used for TCRE.

The internal ostia were identified and corresponding endometrium was resected with bipolar resectoscope using current settings of 80 , followed by successive resection of endometrium of the fundus and the anterior and posterior uterine wall. Fluid balance was checked throughout the procedure.

It was performed under spinal anaesthesia.

\section{Statistical analysis}

Following were recorded at 3-month intervals for a period of 12 months;

- $\quad$ Procedure-related complications

- PBAC score

- Haemoglobin levels

- Adverse effects, rates of acceptability and satisfaction.

\section{RESULTS}

The Table 1 shows the mean age and mean parity in both groups. The mean parity in the TCRE group was 3.2.

The Table 2 shows the etiological distribution in both the groups. Leiomyoma (Fibroids) was the commonest cause of AUB among our patients common in both the groups followed by Ovulatory dysfunction.

Table 1: Age and parity distribution.

\begin{tabular}{|lll|}
\hline Patient variable & LNG-IUS $(\mathbf{N}=17)$ & TCRE $(\mathbf{N}=32)$ \\
\hline Mean age (years) & 38.2 & 40.8 \\
\hline Mean parity & 1.8 & 3.2 \\
\hline
\end{tabular}

Table 2: Etiology of AUB.

\begin{tabular}{|lllll|}
\hline Etiology & Ovulatory dysfunction & Fibroid & Adenomyosis & Endometrial hyperplasia \\
\hline LNG-IUS & 5 & 5 & 4 & 3 \\
\hline TCRE & 9 & 10 & 7 & 6 \\
\hline Percentage & $29 \%$ & $31 \%$ & $22 \%$ & $18 \%$ \\
\hline
\end{tabular}

Table 3: Results at 6 weeks.

\begin{tabular}{|llll|}
\hline Menstrual pattern (6 weeks) & LNG-IUS & TCRE & Percentage \\
\hline Regular cycles & 5 & 1 & $14 \%$ \\
\hline Spotting & 1 & 1 & $5 \%$ \\
\hline Infrequent cycles + scanty menses & 6 & 1 & $16 \%$ \\
\hline Amenorrhoea & 1 & 25 & $60 \%$ \\
\hline HMB & 2 & 0 & $5 \%$ \\
\hline
\end{tabular}

Table 4: Results at 6 months.

\begin{tabular}{|llll|}
\hline Menstrual pattern (6 weeks) & LNG-IUS & TCRE & Percentage \\
\hline Regular cycles & 4 & 1 & $3 \%$ \\
\hline Spotting & 1 & 0 & $7 \%$ \\
\hline Infrequent cycles + scanty menses & 3 & 0 & $79 \%$ \\
\hline Amenorrhoea & 7 & 27 & $0 \%$ \\
\hline HMB & 0 & 0 & - \\
\hline Expelled & 0 & - & $7 \%$ \\
\hline
\end{tabular}


Table 5: Results at 12 months.

\begin{tabular}{|llll|}
\hline Menstrual pattern (12 months) & LNG-IUS & TCRE & Percentage \\
\hline Regular cycles & 2 & 1 & $7 \%$ \\
\hline Spotting & 0 & 0 & $0 \%$ \\
\hline Infrequent cycles + scanty menses & 1 & 0 & $3 \%$ \\
\hline Amenorrhoea & 12 & 27 & $90 \%$ \\
\hline HMB & 0 & 0 & $0 \%$ \\
\hline Removed & 0 & - & - \\
\hline
\end{tabular}

Table 6: Adverse effects.

\begin{tabular}{|lll|}
\hline Duration of bleeding (days) & LNG-IUS & TCRE \\
\hline Prior to intervention & 6.8 & 7.2 \\
\hline Post 6 months & 2.7 & 2.6 \\
\hline Post 12 months & 2.2 & 3.0 \\
\hline Reduction at 6 months & 4.1 & 4.6 \\
\hline Reduction at 12 months & 4.6 & 4.2 \\
\hline
\end{tabular}

Table 7: Subsequent treatment after failure.

\begin{tabular}{|lll|}
\hline Treatment options & Number & Percentage \\
\hline Hysterectomy & 2 & $5 \%$ \\
\hline Hormonal therapy & 0 & $0 \%$ \\
\hline TCRE $\rightarrow$ LNG-IUS & 0 & $0 \%$ \\
\hline LNG-IUS $\rightarrow$ TCRE & 2 & $5 \%$ \\
\hline
\end{tabular}

Table 8: Satisfaction and acceptability.

\begin{tabular}{|lll|}
\hline & LNG-IUS & TCRE \\
\hline Reduction in menstrual blood loss & $85.7 \%$ & $87.6 \%$ \\
\hline Satisfaction and acceptance rates & $83.2 \%$ & $88.4 \%$ \\
\hline
\end{tabular}

Table 9: Efficacy in terms of duration of bleeding.

\begin{tabular}{|lll|}
\hline Duration of bleeding (days) & LNG-IUS & TCRE \\
\hline Prior to intervention & 6.8 & 7.2 \\
\hline Post 6 months & 2.7 & 2.6 \\
\hline Post 12 months & 2.2 & 3.0 \\
\hline Reduction at 6 months & 4.1 & 4.6 \\
\hline Reduction at 12 months & 4.6 & 4.2 \\
\hline
\end{tabular}

Table 3, 4, 5 show the results at the end of 6 weeks, 6 months and 12 months. In the TCRE group amenorrhoea was seen at 6 weeks itself and by the end of 12 months $90 \%$ of patients in the TCRE group had amenorrhoea. The table no. 6 shows the adverse effects in both the groups. The duration of bleeding was reduced to 4.6 days in the LNG-IUS group and 4.2 days in the TCRE group. The Table 7 shows that $5 \%$ of patients subsequently required hysterectomy and 5\% of patients treated with LNG-IUS subsequently required TCRE. After a year their reductions of $85.7 \%$ and $87.6 \%$ in menstrual blood loss in TCRE and LNG-IUS groups, respectively as shown in Table 8 .
Amenorrhoea was more common in TCRE group while spotting and systemic effects were more common in LNG-IUS group.

Satisfaction and acceptance rates higher in TCRE group as shown in Table 9.

\section{Advantages of LNG-IUS over TCRE}

- It can be performed as an office procedure

- LNG-IUS insertion is non-operative and hence virtually devoid of operative complications, such as excessive trauma and bleeding 
- There is no need for anaesthesia, cervical dilatation, antibiotics

- Does not preclude future fertility

- Cost-effective.

\section{DISCUSSION}

Heavy menstrual bleeding has since long been a major health problem affecting the quality of life of women all over the world.

Hysterectomy was once the only surgical option for heavy menstrual bleeding, and almost half of the hysterectomies currently performed worldwide are carried out for this reason, but it is a major surgical intervention associated with surgical risks and substantial costs. ${ }^{9}$ Endometrial destruction techniques, which aim to destroy or remove the endometrial tissue, include rollerball ablation and trans-cervical resection under direct hysteroscopic vision and second generation nonhysteroscopic techniques. ${ }^{10}$ LNG-IUS provides a nonsurgical alternative, which is reversible and spares fertility. ${ }^{11}$

The results of this study demonstrate that both LNG-IUS and TCRE clearly reduce menstrual blood loss. Responses to treatment at the end of 1 year follow up showed no significant difference between the two groups ( $85.7 \%$ for LNG-IUS and $87.6 \%$ for TCRE), but the rate of amenorrhea in the TCRE group was higher ( $\mathrm{P}<$ $0.0001)$. These results are similar to study by Ghazizadeh et al. ${ }^{12}$ In the study by Gupta et al, $97 \%$ and $94 \%$ reductions were observed in menstrual blood loss in the LNG-IUS and TCRE groups respectively. ${ }^{13}$ However, Crosignani et al and Istre and Trolle reported a significantly higher reduction in menstrual blood loss with TCRE than with LNG-IUS insertion. ${ }^{14,15}$ In our study, amenorrhea was more common in the TCRE group than in LNG-IUS at 12 months posttreatment (84.3\% versus $70.5 \%$ respectively). In Hidalgo et al, $44 \%$ of the women who had LNG-IUS inserted reported amenorrhea at the $6^{\text {th }}$ month of use. This rate-maintained stability in $50 \%$ of these women after 12 and 24 months of use and spotting was present in $25 \%$ of the users at 6 months, decreasing to $11 \%$ at 24 months. This rate-maintained stability at $50 \%$ after 12 and 24 months of use. ${ }^{16}$

\section{CONCLUSION}

Though the patient satisfaction was almost the same in both the groups, the advantage of LNG-IUS is it is less invasive.

\section{ACKNOWLEDGMENTS}

Authors would like to acknowledge Dr. G. S. Shekhawat, Professor and Head of Department, Obstetrics and Gynaecology, Smt. Kashibai Navale Medical College and General hospital, Pune Dr. Hemant Damle, Professor, Smt. Kashibai Navale Medical College and General hospital, Pune and the entire facilty of Department of Obstetrics and Gynecology at SKNMCH and GH for their kind support and cooperation.

Funding: No funding sources

Conflict of interest: None declared

Ethical approval: The study was approved by the Institutional Ethics Committee

\section{REFERENCES}

1. Blumenthal PD, Dawson L, Hurskainen R. Costeffectiveness and quality of life associated with heavy menstrual bleeding among women using the levonorgestrel-releasing intrauterine system. Int $\mathbf{J}$ Gynaecol Obstet. 2011;112:171-8.

2. Theodoridis TD, Zepiridis L, Zafrakas M, Grimbizis G, Tantsis A, Kyrou D, et al. Levonorgestrelreleasing intrauterine system vs.endometrial thermal ablation for menorrhagia. Hormones (Athens). 2009;8:60-4.

3. Milsom I. The levonorgestrel -releasing intrauterine system as an alternative to hysterectomy in perimenopausal women. Contraception. 2007;75(6 Suppl):S152.

4. Endrikat J, Vilos G, Muysers C, Fortier M, Solomayer E, Lukkari-Lax E. The levonorgestrelreleasing intrauterine system provides a reliable, long-term treatment option for women with idiopathic menorrhagia. Arch Gynecol Obstet. 2012;285:117-21.

5. Tariq N, Ayub R, Jaffery T, Rahim F, Naseem F, Kamal M. Efficacy of levonorgestrel intrauterine system (LNG-IUS) for abnormal uterine bleeding and contraception. J Coll Physicians Surg Pak. 2011;21:210-3.

6. Vilos GA, Marks J, Tureanu V, Abu-Rafea B, Vilos AG. The levonorgestrel intrauterine system is an effective treatment in selected obese women with abnormal uterine bleeding. J Minim Invasive Gynecol. 2011;18:75-80.

7. Rodriguez MI, Darney PD. Non-contraceptive applications of the levonorgestrel intrauterine system. Int J Womens Health. 2010;2:63-8.

8. American College of Obstetricians and Gynecologists Committee on Gynecologic Practice. ACOG committee opinion. No. 337: Noncontraceptive uses of the levonorgestrel intrauterine system. Obstet Gynecol. 2006;107:147982.

9. Maresh MJA, Metcalfe MA, McPherson K, Overton C, Hall V, Hargreaves J. The VALUE national hysterectomy study: description of the patients and their surgery. Br J Obstet Gynaecol. 2002;109:30212.

10. Abbott J, Garry R. The surgical management of menorrhagia. Hum Reprod Update. 2002;8:78.

11. Lethaby AE, Cooke I, Rees M. Progesterone or progestogen-releasing intrauterine systems for heavy 
menstrual bleeding. Cochrane Database Syst Rev. 2005;4:CD002126.

12. Ghazizadeh S, Bakhtiari F, Rahmanpour H, DavariTanha F, Ramezanzadeh F. A randomized clinical trial to compare levonorgestrel-releasing intrauterine system (Mirena) vs trans-cervical endometrial resection for treatment of menorrhagia. Int $\mathbf{J}$ Womens Health. 2011;3:207-11.

13. Gupta B, Mittal S, Misra R, Dek D, Dadhwal V. Levonorgestrel-releasing intrauterine system vs transcervical endometrial resection for dysfunctional uterine bleeding. Inter $\mathbf{J}$ Gynecol Obstet. 2006;95:261-6.

14. Crosignani PG, Vercellini P, Mosconi PM, Sci DB, Oldani S, Cortesi I, et al. Levonorgestrel-releasing intrauterine device versus hysteroscopic endometrial resection in the treatment of dysfunctional uterine bleeding. Obstet Gynecol. 1997;90:257-63.
15. Istre $\mathrm{O}$, Trolle B. Treatment of menorrhagia with the levonorgestrel intra uterine system versus endometrial resection. Fertil Steril. 2001;76:304-9.

16. Hidalgo M, Bahamondes L, Perrotti M, Diaz J, Dantas-Monteiro C, Carlos P. Bleeding patterns and clinical performance of the levonorgestrel releasing intrauterine system (Mirena) up to two years. Contraception. 2002;65:129-32.

Cite this article as: Hol KV, Shastri SS, Magar SS, Darawade SP. A prospective study to compare levonogestrol intrauterine system and trans-cervical resection of endometrium for treatment of abnormal uterine bleeding. Int J Reprod Contracept Obstet Gynecol 2019;8:4919-25. 